\title{
SEALING ABILITY OF BIODENTINE AND SIMVASTATIN FOR REPAIR OF FURCATION PERFORATION USING DYE EXTRACTION METHOD
}

\author{
Neveen A. Shaheen* and Walaa M. Ghoneim*
}

\begin{abstract}
Aim: This study aimed to evaluate the sealing ability of Biodentine and Simvastatin for the repair of furcal perforation using dye extraction method. Materials and Methods: Thirty extracted permanent human mandibular first molars were selected. Access cavities were prepared in all first molars while perforations were made at the furcation areas of only twenty five molars. Grouping of samples was done as follows, Group $1(n=10)$ in which perforations were repaired with Biodentine $^{\mathrm{TM}}$, Group $2(\mathrm{n}=10)$ in which perforations were repaired with Simvastatin, Group 3 $(n=5)$ in which perforations were left unrepaired (positive control) and Group $4(n=5)$ in which no perforations were done (negative control). The sealing ability in four groups was evaluated using dye extraction method. Statistical analysis was done using One-Way ANOVA test to compare the mean values of the different groups then pairwise comparisons were performed using Tukey's posthoc test. Results: The highest dye absorbance was recorded for the positive control group $(0.081$ $\pm 0.013)$ while the lowest value was recorded for the negative control group $(0.003 \pm 0.002)$. The mean value of Biodentine group $(0.025 \pm 0.009)$ was significantly lower than Simvastatin $(0.069 \pm$ 0.011). Conclusion: Sealing ability of Biodentine is significantly better than Simvastatin in furcal perforation repair.
\end{abstract}

KEYWORDS: Biodentine, dye extraction, perforation, sealing ability, Simvastatin

\section{INTRODUCTION}

Perforation is a pathologic or iatrogenic communication between the root canal space and the attachment apparatus. It may be caused by many reasons as extensive carious lesion, pathological resorption and iatrogenic during endodontic procedures. Furcation perforation is most commonly caused by improper use of burs against the pulp chamber floor during access cavity preparation ${ }^{[1]}$.
Perforation repair prognosis depends mainly on time, size, location of perforation as well as the sealing ability of the repairing materials. The ideal perforation repair material should be biocompatible, induce osteogenesis and cementogenesis, have good sealing ability and radiopaque. It should also be completely degraded during the repair process to allow for its replacement by new healthy bone and act as a barrier against which the root canal obturating material can be placed ${ }^{[2]}$.

* Lecturer of Endodontics, Faculty of Dentistry, Tanta University, Tanta, Egypt. 
Repair of perforation defects was done using several materials as; amalgam, calcium hydroxide, glass ionomer cement, zinc phosphate cement, resin modified glass ionomer cement, indium foil, gutta-percha, tricalcium phosphate, dentin chips, hydroxyapatite, super ethoxy benzoic acid, composite resin, and calcium enriched mixture cement ${ }^{[3-7]}$.

As an alternative material to calcium hydroxide, Mineral trioxide aggregate (MTA) was introduced with many advantages as antimicrobial action, biocompatibility, good sealing ability, low cytotoxicity, and ability to set in the presence of blood and moisture contamination. However, MTA still has many drawbacks as long setting time, and difficult handling characteristics ${ }^{[8-10]}$. So, various calcium silicate-based materials (CSMs) have been developed as alternatives to improve its potential disadvantages ${ }^{[11-13]}$.

Biodentine (BD) is relatively new calcium silicate-based material which was introduced as dentin substitute material; it is mainly composed of tricacium silicate, calcium carbonate, zirconium dioxide and calcium chloride as an accelerator to reduce its setting time ${ }^{[1]}$. It's clinically indicated for permanent dentine replacement, pulp capping, repair of root perforation and resorptive defects, retrograde filling and apexification ${ }^{[14]}$.

None of the currently existing perforation repair materials were able to reestablish the normal architecture in furcal perforations areas. Therefore, there is a necessity for introduction of newer perforation repair materials. Simvastatin is a 3 hydroxy 3-methyl-glutaryl-coenzyme A (HMG$\mathrm{CoA}$ ) reductase inhibitor which is cholesterol lowering drug that has been used to reduce the risk of cardiovascular disease. Many studies have recommended simvastatin as a useful material in vital pulp therapy as it exerts a powerful antiinflammatory effect that prevents the inflammatory process induced by lipopolysaccharide (LPS) ${ }^{[15,16]}$.
Moreover, Simvastatin is bioinductive material that improves the osteoblastic function resulting in enhanced bone formation ${ }^{[17]}$ which is a property required in perforation repair materials.

Sealing ability of furcation repair materials can be assessed by different leakage models including fluid infiltration, dye penetration, bacterial leakage models, dye extraction, air pressure method, an electrochemical method, radioisotope method, metal solution tracers, reverse diffusion method and three dimensional methods ${ }^{[18]}$. In dye extraction methods, teeth are dissolved in acids that release all the dye from the interface and optical density of the solution is measured by spectrophotometer ${ }^{[19]}$.

There is no available information in endodontic literature about the ability of Simvastatin to seal furcal perforations. Therefore, the purpose of this study was to evaluate the sealing ability of Biodentine and Simvastatin in repair of furcation perforation using dye extraction method.

\section{MATERIALS AND METHODS}

Thirty freshly extracted human permanent mandibular first molars with intact furcations were included in this study; these teeth were extracted due to periodontal disease. The exclusion criteria include cracked teeth and those with the extensive carious decay of the crown. The purpose of the study was explained to the patients and informed consents were obtained to use their extracted teeth in the research according to the guidelines adopted by the Research Ethics Committee at Faculty of Dentistry, Tanta University. Teeth were cleaned by removing the hard deposits using curettes and the soft tissues were dissolved by soaking them in $5.25 \%$ sodium hypochlorite (Clorox Co., $10^{\text {th }}$ of Ramadan, Egypt) for $10 \mathrm{~min}$ and then stored in daily-changed normal saline solution until they were used.

The mesial and distal roots of each molar were amputated $3 \mathrm{~mm}$ apical to the furcation area using a diamond disc (Komet; Brasseler, Lemgo, Germany) held at slow speed contrangle handpiece (NSK, 
Tokyo, Japan) under water cooling. Standard coronal access cavity was prepared in the occlusal surface of each molar with round bur size 3 (Dentsply Maillefer, Tulsa, Oklahoma, USA) at high speed contrangle handpiece (NSK, Tokyo, Japan) and root canal orifices were located with DG 16 endodontic explorer (API, Germany).

Canal orifices and the apical end of each root were acid etched with $37 \%$ phosphoric acid gel (3M ESPE Dental Products, St. Paul, MN, USA) for 30 seconds, washed and dried. Then, Adper Single Bond 2 (3M ESPE Dental Products, St. Paul, MN, USA) was applied in two successive coats and light cured using light curing device (Hilux, Benlioglu Inc, Ankara, Turkey) for 20 seconds. The canal orifices and the apical end of each root were then sealed with Filtek ${ }^{\mathrm{TM}} \mathrm{Z} 350$ XT flowable composite (3M ESPE, USA) and cured for 40 seconds according to the manufacturer instructions (Fig.1a). To increase the marginal seal, two successive layers of clear nail varnish were applied on all cavity walls and pulpal floor of each molar ${ }^{[20,21]}$

\section{Preparation of furcal perforations}

All the teeth roots were placed into putty form of silicone impression material (Speedex ${ }^{\circledR}$ Coltene ${ }^{\circledR}$, Switzerland) before polymerization to provide a simulated bony socket around their roots after setting. An artificial perforation was prepared nearly in the center of the floor of the pulp chamber of twenty five teeth (Fig.1b) using $0.5 \mathrm{~mm}$ round bur (Dentsply Maillefer, Tulsa, Oklahoma, USA) with the slow speed handpiece under water cooling to standardize the size of perforation ${ }^{[20]}$.

\section{Grouping of samples}

The teeth were randomly divided into four groups, Group 1: ten molars in which the perforations were repaired with Biodentine ${ }^{\mathrm{TM}}$ (Septodont, SaintMaur des Fosses, France). Group 2 consisted of ten molars, in which the perforations were repaired with simvastatin (Sigma-Aldrich, St. Louis, MO, USA). Group 3 represented the positive control which consisted of five molars in which perforations were left unsealed while Group 4 represented the negative control, which consisted of five molars without perforations.

\section{Repair of perforations}

In Group 1, perforation repair was performed with BD material in which a single dose container of liquid was twisted open and five drops were poured into the powder capsule and mixed for 30 seconds in amalgamator (Softly8; de Gotzen, Italy) according to the manufacturer's instructions. The capsule was opened and the material was carried with an amalgam carrier and compacted with a hand plugger (Dentsply Maillefer, Tulsa, Oklahoma, USA) at the site of perforation and covered with moistened cotton pellet.

Simvastatin powder was mixed with distilled water to form a creamy mixture and then delivered to the perforation site using a plastic instrument and compacted with a hand plugger (Fig.1c). After sealing of perforations, the samples were kept in $100 \%$ humidity for 24 hours to allow the materials to set.

\section{Measurement of microleakage using dye extrac- tion method}

One drop of $2 \%$ methylene blue dye (2 $\mathrm{g}$ in 100 $\mathrm{ml}$ distilled water) was dispensed into the access cavities of all teeth using eye dropper and kept for the next 24 hours. The teeth were rinsed under tap water for $30 \mathrm{~min}$. to remove any residues of the dye. Then, the varnish was scraped using Bard Parker blade no. $15^{[22]}$.

Each tooth was stored in hermitically sealed vial containing $2 \mathrm{ml}$ of $65 \%$ concentrated nitric acid for three days; the supernatant solution from each tooth was then centrifugated for $5 \mathrm{~min}$. at $14000 \mathrm{rpm}$ to release the dye. After centrifugation, the resulting supernatant was analyzed using UV spectrophotometer (UniCo 7200, Shanghi, China) at $550 \mathrm{~nm}$ to determine optical density of dye 


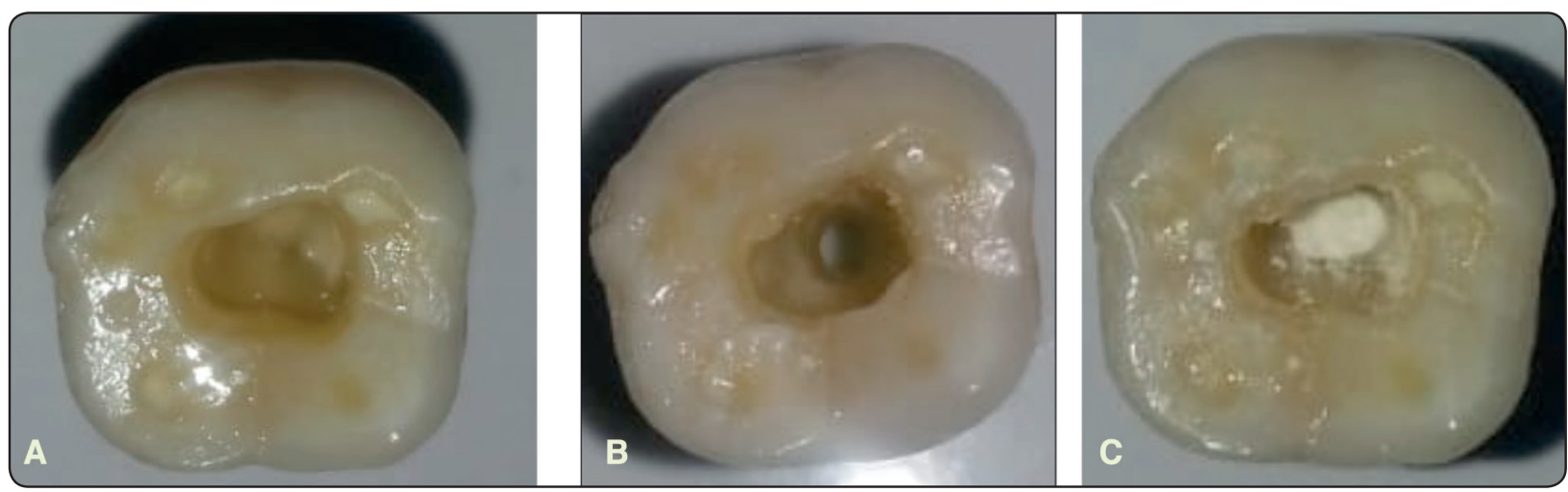

Fig. (1) A mandibular first molar after access cavity preparation and sealing of canal orifices with flowable composite (a), after furcal perforation(b), after perforation repair using simvastatin(c)

absorbance values ${ }^{[13]}$, using concentrated nitric acid as a blank ${ }^{[23]}$.

\section{Statistical analysis}

One-Way ANOVA test was used to compare the mean optical density of dye absorbance values of the different groups at significance level of $P \leq$ 0.05 . Then multiple pairwise comparisons between groups were performed using Tukey's post-hoc test using SPSS software version 24 (SPSS inc, Chicago, USA).

\section{RESULTS}

The mean optical density of dye absorbance values and their respective standard deviations $(\mathrm{SD})$ in all groups were shown in Table 1. The highest dye absorbance was recorded for the positive control group while the lowest value for the negative control group as shown in Table 1 and Fig.2.

One-Way ANOVA test revealed a statistically significant difference among the tested groups. Multiple pairwise comparisons showed that Group 1 using BD was statistically significant than Group 2 (Simvastatin group) and both control groups. In addition, Group 2 was statistically significant than negative control group whereas there was no statistically significant difference between Group 2 and positive control group (Table 2).
TABLE (1) Mean optical density and standard deviations of dye absorbance values

\begin{tabular}{|c|c|c|c|}
\hline Groups & $\begin{array}{c}\text { no. of } \\
\text { samples }\end{array}$ & Mean \pm SD & \multirow{2}{*}{-value } \\
\cline { 1 - 3 } Group 1 & 10 & $0.025^{\mathrm{b}} \pm 0.009$ & \multirow{2}{*}{$<0.0001$} \\
\cline { 1 - 3 } Group 2 & 10 & $0.069^{\mathrm{a}} \pm 0.011$ & \\
\cline { 1 - 3 } $\begin{array}{c}\text { Group 3 } \\
\text { (positive control) }\end{array}$ & 5 & $0.081^{\mathrm{a}} \pm 0.013$ & \\
\cline { 1 - 2 } $\begin{array}{c}\text { Group 4 } \\
\text { (negative control) }\end{array}$ & 5 & $0.003^{\mathrm{c}} \pm 0.002$ & \\
\hline
\end{tabular}

Mean values with the same superscript letters are not statistically significant at $P \leq 0.05$

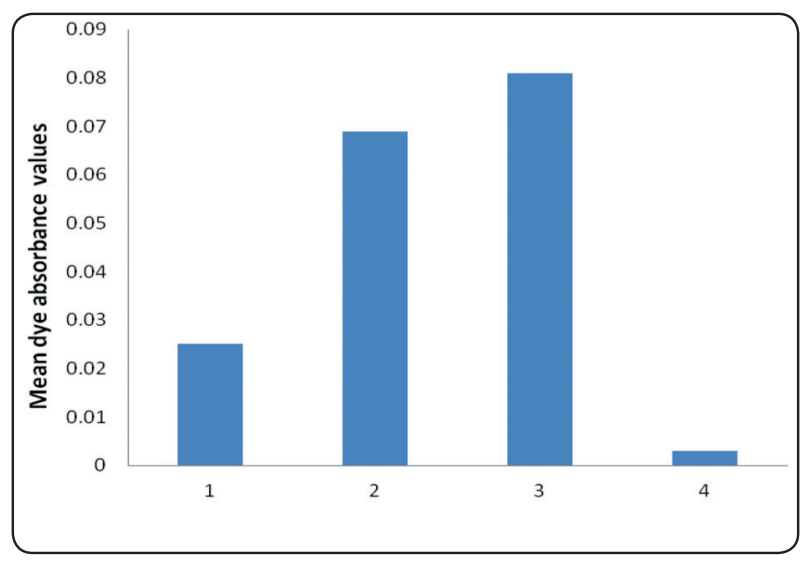

Fig. (2) Bar chart showing mean optical density of dye absorbance values in all groups 
TABLE (2) Tukey's post-hoc test pairwise comparisons for significant differences among four tested groups.

\begin{tabular}{|l|l|}
\hline Intergroup comparisons & P-value \\
\hline Group 1 versus Group 2 & $<0.0001$ \\
\hline Group 1 versus Group 3 & $<0.0001$ \\
\hline Group 1 versus Group 4 & 0.0125 \\
\hline Group 2 versus Group 3 & 0.2500 \\
\hline Group 2 versus Group 4 & $<0.0001$ \\
\hline Group 3 versus Group 4 & $<0.0001$ \\
\hline
\end{tabular}

\section{DISCUSSION}

Furcal perforations, most commonly occur during access cavity preparation, can cause secondary inflammation of the periodontal attachment which lead to loss of tooth if not treated ${ }^{[24]}$. In the management of furcal perforations, it is important to arrest the inflammatory process and loss of tissue attachment at the site of the perforation ${ }^{[25]}$. Simvastatin enhances bone morphogenic protein-2 which leads to increase in bone density and stimulates periodontal cells differentiation ${ }^{[26]}$. It has also anti-resorption action by blocking mevalonate pathway through inhibition of enzyme HMG-CoA reductase. Additionally, it increases levels of alkaline phosphatase, osteopontin and osteocalcin which are osteoblast differentiation markers ${ }^{[27]}$. So, it was tested in this study as it has desirable properties required for ideal perforation repair material.

Sealing ability of simvastatin in furcal perforation repair was tested in this study in comparison to $\mathrm{BD}$ as it was not previously investigated regarding this point in addition to the fact that the degree of tissue response to repaired perforations depends on several factors among them the sealing ability of repair materials ${ }^{[4]}$.
Dye extraction method provides more reliable results than dye penetration method since it measures all the dye taken up in the root quantitatively ${ }^{[28]}$. Additionally, it is better than fluid filtration as it is not diminished by time ${ }^{[29]}$. Therefore, in the present study, microleakage was checked using dye extraction method.

The microleakage results are adversely affected by the compatibility of the dye materials and tested materials. The dyes used for assessing microleakage with dye extraction method in other studies are either methylene blue ${ }^{[30,31]}$ or basic fuchsin ${ }^{[32,33]}$. Thus, methylene blue dye has been determined spectrophotometrically in this study.

The results of the present study showed that the lowest dye absorbance with negative control group (0.003) which was close to nitric acid (blank) with a value of zero. The positive control group had the highest dye absorbance (0.081) value of all tested groups which showed the accuracy of the technique ${ }^{[31]}$.

In Group 1 using BD; the mean optical density of dye absorbance value was significantly lower than Group 2 (Simvastatin group) and positive control group. This could be attributed to the development of a hydroxyapatite-like layer between dentine and CSMs through the hydration reaction of CSMs suggesting formation of a chemical bond ${ }^{[34]}$. In addition to its micro-mechanical anchorage to tooth structure ${ }^{[35]}$, its compressive strength, hardness and modulus of elasticity which is close to that reported for human dentine. Moreover, its chemical composition does not contain aluminates that lead to weakening and fragility of the set material ${ }^{[36]}$. Moreover BD is stable, less soluble, non-resorbable, hydrophilic and produces a tight seal ${ }^{[37]}$. These results were supported by Sinkar et al ${ }^{[38]}$ and Katge et $\mathrm{al}^{[1]}$ who reported good sealing ability of BD in furcal perforations and Mir et al ${ }^{[39]}$ who found that the sealing ability of BD is significantly better than MTA and bioactive bone cement. 
On the other hand, Group 2 using simvastatin was not significantly different than positive control group which indicate poor sealing ability of this material. This may be due absence of any physical or chemical bond to tooth structure.

\section{CONCLUSIONS}

The sealing ability of Simvastatin is lower comparable to that of Biodentine in repair of furcation perforation.

Further studies should be conducted to test mixture of simvastatin with other biomaterials capable of bonding to tooth structure without affecting other properties of both materials

\section{REFERENCES}

1. Katge FA, Shivasharan PR, Patil D. Sealing ability of mineral trioxide aggregate Plus ${ }^{\mathrm{TM}}$ and Biodentine ${ }^{\mathrm{TM}}$ for repair of furcal perforation in primary molars: An in vitro study. Contemp Clin Dent 2016; 7: 487-92.

2. Dazey S, Senia ES. An in vitro comparison of the sealing ability of materials placed in lateral root perforations. J Endod 1990; 16:19-23.

3. Asgary S. Furcal perforation repair using calcium enriched mixture cement. J Conserv Dent 2010; 13:156-8.

4. Alhadainy HA, Himel VT. Evaluation of the sealing ability of amalgam, Cavit, and glass ionomer cement in the repair of furcation perforations. Oral Surg Oral Med Oral Pathol $1993 ; 75: 362-6$

5. Nakata TT, Bae KS, Baumgartner JC. Perforation repair comparing mineral trioxide aggregate and amalgam using an anaerobic bacterial leakage model. J Endod 1998; 24:184-6.

6. Jantarat J, Dashper SG, Messer HH. Effect of matrix placement on furcation perforation repair. J Endod 1999; 25:192-6.

7. Arens DE, Torabinejad M. Repair of furcal perforations with mineral trioxide aggregate: Two case reports. Oral Surg Oral Med Oral Pathol Oral Radiol Endod 1996; 82: 84-8.

8. Torabinejad M, Smith $\mathrm{P}$, Kettering J, Pitt Ford T. Comparative investigation of marginal adaptation of mineral trioxide aggregate and other commonly used rootend filling materials. J Endod 1995 Jun; 21(6):295-299.

9. Torabinejad M, Chivian N. Clinical applications of mineral trioxide aggregate. J Endod 1999 Mar; 25(3):197-205.

10. Boutsioukis C, Noula G, Lambrianidis T. Ex vivo study of the efficiency of two techniques for the removal of mineral trioxide aggregate used as a root canal filling material. $\mathrm{J}$ Endod 2008; 34(10):1239-1242.

11. Gomes-Filho J, Rodrigues G, Watanabe S, Estrada Bernabé PF, Lodi CS, Gomes AC, Faria MD, Domingos Dos Santos A, Silos Moraes JC. Evaluation of the tissue reaction to fast endodontic cement (CER) and Angelus MTA. J Endod 2009; 35(10):1377-1380

12. Camilleri J. Characterization and hydration kinetics of tricalcium silicate cement for use as a dental biomaterial. Dent Mater 2011; 27(8):836-844.

13. Grecha L, Malliaa B, Camilleri J. Investigation of the physical properties of tricalcium silicate cement-based root-end filling materials. Dent Mater 2013; 29(2):e20-e28.

14. Nayak G,Hasan MF. Biodentine-a novel dentinal substitute for single visit apexification. Restor Dent Endod. 2014; 39:120-5.

15. Jung JY, Woo SM, Kim WJ, Lee BN, Nör JE, Min KS, et al. Simvastatin inhibits the expression of inflammatory cytokines and cell adhesion molecules induced by LPS in human dental pulp cells. Int Endod J 2017; 50:377-386.

16. Hernandez-Romero MC, Arguelles S, Villaran RF et al. Simvastatin prevents the inflammatory process and the dopaminergic degeneration induced by the intranigral injection of lipopolysaccharide. Journal of Neurochemistry 2008; 105: 445-59.

17. Mundy G, Garrett R, Harris S et al. Stimulation of bone formation in vitro and in rodents by statins. Science 1999; 286: 1946-9.

18. Muliyar S, Shameem KA, Thankachan RP, Francis PG, Jayapalan CS, Hafiz KA. Microleakage in endodontics. J Int Oral Health 2014;6: 99-104.

19. 19. Sheetal M, Amit P, Dhairaysheel E, Amit C, Abhijit P, Rahul S. Methodologies for assessing root canal sealing: A review. IJOCR 2015; 3:55-58.

20. De-Deus G, Reis C, Brandão C, Fidel S, Fidel RA. The ability of Portland cement, MTA, and MTA Bio to prevent through-and-through fluid movement in repaired furcal perforations. J Endod 2007; 33:1374-7. 
21. De-Deus G, Petruccelli V, Gurgel-Filho E, Coutinho-Filho T. MTA versus Portland cement as repair material for furcal perforations: A laboratory study using a polymicrobial leakage model. Int Endod J 2006; 39: 293-298.

22. Hashem AA, Hassanien EE. ProRoot MTA, MTA-Angelus and IRM used to repair large furcation perforations: Sealability study. J Endod 2008; 34:59-61.

23. Camps J, Pashley D. Reliability of the dye penetration studies. J Endod 2003; 29: 592-594.

24. Fuss Z, Trope M. Root perforations: Classification and treatment choices based on prognostic factors. Endod Dent Traumatol 1996; 12: 255-64.

25. Main C, Mirzayan N, Shabahang S, Torabinejad M. Repair of root perforations using mineral trioxide aggregate: A long-term study. J Endod 2004; 30:80-3.

26. Yazwa H, Zimmermann B, Asami Y, Bernimoulin J. Simvastatin promotes cell metabolism proliferation and osteoblastic differentiation in human periodontal ligament cells. J Periodontol 2005;76:295-302.

27. 27. Pradeep AR, Thorat MS. Clinical effect of subgingivally delivered simvastatin in treatment of patients with chronic periodontitis: a randomized clinical study. J Periodontol 2010;81:214-222

28. 28. Hamad HA, Tordik PA, McClanahan SB. Furcation perforation repair comparing gray and white MTA: A dye extraction study. J Endod 2006; 32:337-40.

29. Tandan M, Hegde MN, Hegde P. Effect of four different intracanal medicaments on the apical seal of root canal system: A dye extraction study. IJDR 2014; 25:607-612.

30. Balachandran J, Gurucharan. Comparison of sealing ability of bioactive bone cement, mineral trioxide aggregate and super EBA as furcation repair materials: A dye extraction study. J Conserv Dent 2013; 16:247-51.

31. Jeevani E, Jayaprakash T, Bolla N, Vemuri S, Sunil CR, Kalluru RS. Evaluation of sealing ability of MM-MTA,
Endosequence, and biodentine as furcation repair materials: UV spectrophotometric analysis. J Conserv Dent 2014; 17:340-3.

32. Sanghavi T, Shah N, Shah RR. Comparative analysis of sealing ability of Biodentin and Calcium phosphate cement against Mineral Trioxide Aggregate (MTA) as a furcal perforation repair material: An in-vitro study. Natl J Integr Res Med 2013; 4:56-60.

33. Vanni JR, Della-Bona A, Figueiredo JA, Pedro G, Voss D, Kopper PM. Radiographic evaluation of furcal perforations sealed with different materials in dogs' teeth. J Appl Oral Sci 2011; 19:421-425.

34. Han L, Okiji T. Bioactivity evaluation of three calcium silicate-based endodontic materials. Int Endod J. 2013;46: 808-14.

35. Arora V, Nikhil V, Sharma N, Arora P. Bioactive dentin replacement. IOSR-JDMS. 2013;12: 51-57.

36. Butt N, Talwar S, Chaudhry S, Nawal RR, Yadav S, Bali A. Comparison of physical and mechanical properties of mineral trioxide aggregate and Biodentine. Indian J Dent Res. 2014; 25:692-7.

37. Bachoo IK, Seymour D, Brunton P. A biocompatible and bioactive replacement for dentine: is this a reality? The properties and uses of a novel calcium-based cement. $\mathrm{Br}$ Dent J. 2013;214:E5.

38. Sinkar RC, Patil SS, Jogad NP, Gade VJ. Comparison of sealing ability of ProRoot MTA, RetroMTA, and Biodentine as furcation repair materials: An ultraviolet spectrophotometric analysis. J Conserv Dent 2015; 18: $445-8$

39. Mir A, Misgar OH, Farooq R, Purra AR, Ahanger FA. Comparison of sealing ability of biodentine, bioactive bone cement and MTA as furcation repair materials. IOSR journal of dental and medical sciences (IOSR-JDMS) 2017;16:82-86. 